\title{
A CONSTRUÇÃO DO DIREITO À SAÚDE NO BRASIL: O PLANO DE FUNDO ANTECENTE À SUA POSITIVAÇÃO CONSTITUCIONAL
}

\author{
Beatriz Casagrande Fortunato* \\ Carla Roberta Ferreira Destro**
}

\section{RESUMO}

O presente trabalho detém o escopo de demonstrar a evolução dos direitos fundamentais e sua importância na sociedade contemporânea, principalmente, do direito à saúde, direito fundamental e social, positivado na Constituição de 1988. Entretanto, antes dela, já possuía atenção por parte do Poder Público e da sociedade civil, a partir de ações e políticas voltadas à saúde pública, aliadas a magnitude e relevância dos direitos humanos no contexto internacional e a redemocratização no Brasil foram determinantes para a construção e concretização do direito à saúde no cenário nacional. Destarte, o presente trabalho foi desenvolvido mediante a utilização do método dedutivo.

Palavras-chave: Ações Governamentais; Direitos Fundamentais; Direito à Saúde; Constituição; Sistema Único de Saúde.

\section{THE DEVELOPMENT OF THE RIGHT TO HEALTH IN BRAZIL: THE BACKGROUD THAT PRECEDE ITS CONSTITUCIONAL REGULAMENTATION}

ABSTRACT: This article objective is to show the evolution of the fundamental rights and their value in the contemporary society, mainly, the right to health, a fundamental and social right, regulated by the Constitution of 1988, however, before, it already had attention by the goverment and the society based on actions and policies aimed at public health, in addicion to the magnitude and relevance of human rights in the international context and redemocratization in Brazil were decisive for the construction and realization of the right to health on the national scenario. Thus, the present work was developed using the deductive method.

Keywords: Governamental Actions; Fundamental Rights; Right to Health; Constitucion;

\section{INTRODUÇÃO}

\footnotetext{
*Mestranda em Ciências Jurídicas pela Universidade Estadual do Norte do Paraná - UENP. Bolsista CAPES/Fundação Araucária. Formada em Direito pelo Centro Universitário Eurípedes de Marília - UNIVEM. Endereço postal: Avenida Santo Antônio, 3974, CEP 17507-220, Santa Tereza, Marília, SP. E-mail: bia_fortunato@hotmail.com.

** Mestranda em Ciências Jurídicas pela Universidade Estadual do Norte do Paraná -UENP. Pós-Graduada em Direito Civil e Processual Civil pelo Centro Universitário Antônio Eufrásio de Toledo de Presidente Prudente. Endereço postal: Rua Barão do Rio Branco, no 1195, CEP 19015-010, Presidente Prudente, SP. E-mail: carladestroadv@gmail.com.
} 
O Direito tem, dentre suas inúmeras funções, a de normatizar e organizar a vida social. Posto isso, o Direito e os direitos fundamentais, as regras e as normas advêm ou se baseiam em acontecimentos históricos.

Por isso, quando se trata de direitos fundamentais e sociais, é preciso conceber que eles são provenientes da luta humana em determinados momentos da história, sendo conquistas, que a partir de sua positivação, pelo Princípio da Proibição do Retrocesso, não podem deixar de ser garantidos pelo ordenamento jurídico, sob pena de se retornar a um contexto econômico, político e social (e histórico) de violações e atrocidades.

Igualmente, no caso do direito à saúde, o qual foi positivado pela Constituição Federal Brasileira de 1988, como fruto não só do sistema de garantias que ela adotou em razão do regime militar e dos novos ideais que gravitavam no cenário internacional após duas grandes guerras mundiais e a Guerra Fria se encaminhando para um fim, ele é também resultado das políticas e ações de saúde implementadas anteriormente no país, da insatisfação social e dos pedidos por mudança realizados pela sociedade civil.

Logo, o trabalho busca realizar uma análise do direito à saúde no Brasil, a partir de seu referencial histórico materializado em políticas e ações em prol da saúde realizadas antes de seu reconhecimento na Constituição de 1988, justamente para verificar se existe um padrão, ou ocorreram mudanças ou melhoras na situação da saúde do Brasil após ela se tornar um direito reconhecido e que precisa ser efetivado. Para tanto, foi utilizado o método dedutivo e as técnicas de coleta de dados bibliográficos, documentais e via internet.

\section{CONSIDERAÇÕES ACERCA DOS DIREITOS FUNDAMENTAIS}

Inicialmente, urge destacar que a conquista dos direitos fundamentais, isto é, atributos inerentes ao homem enquanto sujeito, qualificando-o como tal, é resultado de lutas constantes que compõe a história da humanidade. Além do que, eles habitam as Constituições, vez que o constitucionalismo reflete essas lutas e conquistas.

Os "direitos fundamentais são aqueles previstos em uma determinada ordem constitucional, com objetivo de proteger a dignidade da vida humana em todas as suas dimensões", segundo Serrano (2012, p. 12).

Nesse sentido, para Lafer (1997, p. 57), em comunhão com o pensamento de Hannah Arendt: "O valor da pessoa humana como valor-fonte da ordem da vida em sociedade 
encontra a sua expressão jurídica nos direitos humanos. Estes foram, a partir do século XVIII, positivados em declarações constitucionais".

Ou seja, a dignidade da pessoa humana é um valor base para o ser humano e através dela os direitos humanos começam a se manifestar seja de forma individual, coletiva ou difusa.

Cumpre assinalar, que, conforme a doutrina majoritária, apenas a título de diferenciação, os direitos humanos são os direitos ou atributos que compõem o ser humano, especialmente resguardados em documentos internacionais, enquanto os direitos fundamentais simbolizam os direitos previstos nas Constituições dos países.

O ideário dos direitos humanos começou a se desenvolver com o Cristianismo, em São Tomás de Aquino, eis que a partir da concepção jusnaturalista se pensava que o homem possuía direitos básicos, os quais deveriam ser respeitados e operavam como limitações ao poder absolutista e monárquico. Esses direitos, apesar de serem dispersos, compuseram documentos como a Magna Carta de João Sem Terra (1215), a Petition of rights (1628) e o Habeas Corpus Act (1679), assegurando alguns direitos aos cidadãos, porém sem caráter universal, apenas protegendo grupos específicos (SERRANO, 2012, p. 14-15).

No tocante a positivação dos direitos humanos, tem-se que:

\begin{abstract}
O elenco dos direitos humanos contemplados pelo Direito Positivo foi se alterando do século XVIII até os nossos dias. Assim caminhou-se historicamente dos direitos humanos de primeira geração - os direitos civis e políticos de garantia, de cunho individualista voltados para tutelar a diferença entre Estado e Sociedade e impedir a dissolução do indivíduo num todo coletivo - para os direitos de segunda geração os direitos econômicos, sociais e culturais concebidos como créditos dos indivíduos com relação à sociedade, a serem saldados pelo Estado em nome da comunidade nacional. O processo de asserção histórica das duas gerações de direitos humanos, que são direitos de titularidade individual, foi inspirado pelos legados cosmopolita e universalista do liberalismo e do socialismo (LAFER, 1997, p. 57).
\end{abstract}

A origem dos direitos humanos remonta a filosofia e jusnaturalismo na época do Cristianismo, diante da concepção de que os indivíduos seriam portadores de direitos básicos e fundamentais, no entanto tal proteção se restringia a grupos específicos.

Outrora, a partir do século XVIII foi se desenhando a aquisição dos direitos fundamentais pelo Direito, ou seja, houve a positivação desses direitos, inicialmente de forma individual, a partir dos direitos de liberdade, e em um segundo momento, de forma coletiva, isto é, considerando a igualdade e a coletividade ou determinados grupos sociais. 
Após duas grandes guerras, o movimento constitucionalista de valorização de direitos (com a Constituição alemã de 1949, a francesa de 1958, a portuguesa de 1976, a espanhola de 1978 e a brasileira de 1988), passou-se a conceber uma cultura constitucional social e dirigente, importando-se com a solidariedade, a fraternidade e a humanidade em seu sentido difuso, razão pela qual surge a terceira dimensão dos direitos fundamentais. Assim, os direitos de terceira geração são "ligados à proteção da própria coletividade, ao meio ambiente, aos direitos sociais ou econômicos (direitos coletivos ou difusos)" (SERRANO, 2012, p. 23).

Por outro lado, interessante salientar que os direitos fundamentais se apresentam como limites ao poder do Estado:

\footnotetext{
Os direitos fundamentais representam a tradicional tutela das liberdades burguesas: liberdade pessoal, política e econômica. Constituem um dique contra a intervenção do Estado. Pelo contrário, os direitos sociais representam direitos de participação no poder político e na distribuição da riqueza social produzida (BOBBIO; MATEUCCI;PASQUINO, 1998, p. 401).
}

Portanto, os direitos fundamentais são frutos das lutas da burguesia, por liberdade diante do excesso de intervenção econômica do Estado, e logo depois, foram lutas por igualdade de condições perante o acesso ao poder e as outras classes sociais.

Além disso, Comparato (2015, p. 53) acentua que a consciência histórica dos direitos humanos adveio da percepção de que as instituições do governo devem ser utilizadas a serviço dos seus governados, e não em benefício pessoal dos governantes, de forma que os direitos humanos são inerentes a todos e não objeto de concessão dos que exercem o poder.

A seu turno, o reconhecimento dos direitos humanos de caráter social e político se deu a partir do movimento socialista na primeira metade do século XIX. A titularidade desses direitos não é do indivíduo em abstrato, como agradava ao sistema capitalista, mas sim do "conjunto dos grupos sociais esmagados pela miséria, a doença, a fome e a marginalização". Isso porque, os socialistas notaram que essas questões sociais não eram problemas da natureza, ou reflexos da organização e estruturação econômica, eram na verdade resultado do sistema capitalista de produção, o qual "consiste em atribuir aos bens de capital um valor muito superior ao das pessoas" (COMPARATO, 2015, p. 66).

Aliás, a principal característica dos direitos fundamentais é o objetivo de concretização da dignidade humana, motivo pelo qual ela é fundamento do Estado brasileiro. Assim, os direitos trazem consigo "a idéia de proteção e desenvolvimento da pessoa", argumentam Dallari e Nunes Júnior (2010, p. 36). 
Desta feita, os direitos fundamentais representam o núcleo intangível que classifica o homem como tal, além de lhe atribuir posição perante o Estado, a demonstrar que não só o indivíduo, mas os grupos de indivíduos demandam a disposição do Poder Público em seu favor, não obstante a concessão de direitos como mero fruto de comportamentos, eis que eles são expressão da dignidade da pessoa humana (ou pessoas) que os titulariza (m).

Os direitos sociais, por sua vez, têm suas bases no sistema socialista, diante da percepção de grupos marginalizados que não deveriam viver "excluídos” ou vulneráveis, devido a questões econômicas, dada a valorização do dinheiro pelo capitalismo, razão pela qual surge um dos grandes problemas que ainda ocupa a humanidade: a forma ou a melhor maneira de equilibrar direitos e a perpetuação do sistema capitalista.

Nesta toada, é interessante analisar o desenvolvimento de um desses direitos sociais na sociedade brasileira: o direito à saúde, que não foi desde logo positivado e garantido constitucionalmente pelas Constituições que permearam a História do Brasil, ao invés disso, é fruto de ações e políticas em favor da saúde pública no contexto social e político brasileiro.

\section{AS POLÍTICAS E AÇÕES VOLTADAS À SAÚDE ANTES DA CONSTITUIÇÃo DE 1988}

De início, é interessante pontuar que "o Estado brasileiro surgiu como uma metamorfose da Metrópole portuguesa e a nação como uma máscara da Colônia. Daí uma das principais razões entre a assimetria entre as Constituições e as realidades a que se destinavam" (LÉRIAS, 2008, p. 194).

Então, já é possível perceber que haverá uma dissonância entre o texto constitucional brasileiro e a realidade social, marcada por pessoas excluídas da realidade política e econômica das Constituições brasileiras antes da de 1988, de modo que a primeira Carta Magna nacional apenas funcionava como fonte de independência do Brasil Colônia de Portugal.

No período da Primeira República (1889 a 1930), Oswaldo Cruz, como comandante da Diretoria Geral de Saúde Pública, fez com que se implantassem instituições públicas de higiene e saúde pública por todo o país e adotou o modelo "campanhas sanitárias', para combater as epidemias urbanas (em um primeiro momento), e depois as rurais. O modelo campanhista possuía inspiração bélica, com decisões tecnocráticas e um estilo repressivo de intervenção médica nos corpos individual e social. Logo, a estrutura de saúde neste período 
era centralista, tecnoburocrática e corporativista, uma vez que era ligada a um corpo médico oligárquico e agrário dominante na época (LUZ, 1991, p. 78-79).

As Constituições de 1824 e 1891 simbolizaram modificações de aspectos institucionais devido a sua instabilidade, e diante das limitações da sociedade não puderam se tornar espaços de lutas dos seguimentos populares. A Constituição da Primeira República não culminou na garantia da liberdade, sequer na garantia ou outorga dos direitos sociais (GONÇALVES, 2010, p. 93-94).

Por sua vez, a Constituição de 1934 foi a primeira a possuir um título acerca da Ordem Econômica e Social, todavia como resultado de um arranjo político da burguesia industrial e não de lutas sociais, entretanto, diante de um contexto internacional antidemocrático, a Carta era submetida à vontade do governante, e os direitos sociais funcionavam como diretrizes éticas a serem seguidas ao bel-prazer do Poder Executivo (GONÇALVES, 2010, p. 94-95).

Note-se, enfim, que o primeiro resquício de positivação dos direitos sociais se deu na Constituição de 1934, no entanto, a depender das vontades dos que ocupavam o poder. Aliás, as primeiras Constituições brasileiras apenas refletem questões e instabilidades políticas, de modo que a mudança da Carta é fruto de modificações dos que exerciam o poder.

A partir dos anos 30, no período populista, Getúlio Vargas cria os institutos de aposentadorias e pensões em prol dos trabalhadores urbanos mais ligados aos sindicatos e essenciais para a economia agroexportadora dominante, e, no tocante a saúde:

[...] a implantação dos programas e serviços de auxílios e de atenção médica foi impregnada de práticas clientelistas, típicas do regime populista que caracterizou a Era Vargas. Tais práticas se ancoraram também nos sindicatos de trabalhadores, nos quais ajudaram a criar normas administrativas e políticas de pessoal adequadas a estratégias de cooptação das elites sindicais 'simpatizantes' e de exclusão das discordantes, alçando aquelas à direção das instituições e à gestão dos programas governamentais (LUZ, 1991, p. 79).

Eis que, o que se percebe é que a estrutura de saúde favorecia a massa, a relação com os sindicatos e as classes dominantes, em virtude da característica populista de Getúlio Vargas, o que funcionava para que ele se mantivesse no poder, agradando o eleitorado. Resta claro também a relação dos direitos sociais a partir do trabalho, isto é, só os que trabalhavam tinham acesso os serviços de saúde, relacionados especialmente a serviços médicos.

Assim, com a outorga da Carta de 1937, que extinguiu a liberdade, e apenas concedeu alguns direitos sociais, embora obstaculizasse qualquer construção coletiva de tais 
direitos ou espaços de lutas, uma vez que o intuito era de que o Poder Executivo fosse visto e entendido como a principal fonte do exercício do poder (GONÇALVES, 2010, p. 95-96).

Por sua vez, a Constituição de 1946 assegurou liberdades civis e a democracia política, sinalizando que a Constituição poderia deixar de ser um documento eminentemente político para possibilitar a participação popular. Contudo, com um governo autoritário e variadas mazelas sociais, não havia interesse político e apoio popular suficiente para pressionar o governo em favor de uma "emancipação socioeconômica", argumenta Gonçalves (2010, p. 96).

Esclarece Luz (1991, p. 80) que nos anos 50 e 60 houve a tentativa política de se implantar um projeto econômico moderno no sentido capitalista e industrial, em razão da crise do populismo e do nacionalismo. Dessa maneira, as políticas de saúde acompanharam essa realidade, visto que o modelo curativista das prestações previdenciárias estava se mostrando ineficaz aos problemas de saúde urbanos e rurais, visto que consistia em "uma tecnoburocracia médica formada no exterior em administração de serviços de saúde instalouse na gestão dos Institutos de Previdência".

Em 1966, houve a unificação dos institutos de previdência social no Instituto Nacional de Previdência Social (INPS) havendo a cobertura de todos os trabalhadores urbanos assalariados, expandindo, via reflexa, a assistência médica. O governo optou por comprar os serviços da rede privada, culminando no desenvolvimento de um mercado privado de saúde, inclusive porque o governo fornecia subsídios para a construção de unidades hospitalares. Este contexto é o berço dos planos de saúde, pois difunde a ideia de empresas médicas gerindo e realizando assistência médica, como observa Menicucci (2014, p. 79).

Então, o cenário dos direitos sociais, pouco antes dos brasileiros passarem a vivenciar o regime ditatorial, era de algumas garantias, em especial por meio de institutos de previdência, nos quais era fornecida assistência médica aos trabalhadores, porém não muito eficaz. No que tange a saúde, após as mudanças de organização das décadas de 50, havia uma indefinição política acerca de seu financiamento ser inteiramente público ou privado, o que serviu de margem para o surgimento dos planos de saúde futuramente.

Com a piora das condições de vida da população e a impossibilidade de solução pelas instituições, inclusive no tocante a saúde, foi gerado um impasse estrutural entre as políticas sociais e a ordem institucional e política, razão pela qual a elite progressista liderou um grande movimento social no início dos anos 60 no país pleiteando reformas de base imediatas, dentre elas, "uma reforma sanitária consistente e consequente", entretanto, "a 
reação política das forças sociais conservadoras levou ao golpe militar de 1964” (LUZ, 1991, p. 80-81).

Posto isso, as Cartas de 1967 e 1969, no âmbito do regime militar, determinavam direitos fundamentais nos limites do regime, aniquilando as liberdades civis, enquanto os direitos sociais eram tutelados de forma paternalista e residual, servindo como fonte de aceitação e legitimidade do próprio regime (GONÇALVES, 2010, p. 97).

Nesse sentido, Lérias (2008, p. 241) salienta que:

[...] ao mesmo tempo em que direitos civis e políticos eram eliminados praticamente, a ditadura buscava equilibrar-se nos direitos sociais, pois esta foi e é a função da estadania, conceder alguns direitos em substituição às conquistas, pois delas é que nascem os direitos com consistência, avessos às políticas de exceções.

Dessa forma, o regime militar consagrou os direitos sociais como forma de se manter e se legitimar e ainda sim como uma maneira de propagar seus ideais como benéficos, criavase um sentimento de dependência entre o "apoio" ao governo em troca de garantia de direitos que beneficiassem a coletividade, ao passo que sequer eram respeitados direitos básicos e fundamentais de cada um, ou seja, os direitos sociais e sua garantia era uma das máscaras da ditadura como um bom regime para o Brasil. Ressalta-se que há muito na história dos direitos humanos, verificou-se que não basta a garantia dos direitos, cabe ao Estado concretizá-los, algo totalmente contraditório aos propósitos do regime militar.

Ademais, Lérias critica o fato da garantia de direitos sem a luta social pelos mesmos, pois eles se consolidam, tornam-se expressivos e sequer ajudam a compor o sentimento nacional como os direitos que são frutos de luta, compreendidos pelo autor como os que são consistentes e até incompatíveis aos estados de exceção, uma vez que a coletividade está unida e compreende a gravidade da falta de direitos, bem como desses governos militares e autoritários.

Não obstante, em 1974, no governo Geisel, em pleno regime ditatorial, houve uma expansão das políticas previdenciárias e sociais a partir do INAMPS, IAPAS, INPS, DATAPREV, LBA, FUNABEM e a Lei no 6.229, de 17 de julho de 1975, instituiu o Sistema Nacional de Saúde, com uma visão sistêmica e com as mesmas funções e efeitos criticados como políticas de saúde (CORDEIRO, 2004, p. 345).

As escolhas econômicas da época do "milagre econômico" culminaram na "difusão da ideologia do consumo no conjunto da sociedade. A saúde passou, então, a ser vista como 
um bem de consumo. Especificamente, um bem de consumo médico”, de acordo com Luz (1991, p. 82).

E ainda:

\begin{abstract}
No período de 1968 a 1975, generalizou-se a demanda social por consultas médicas como resposta às graves condições de saúde; o elogio da medicina como sinônimo de cura e de restabelecimento da saúde individual e coletiva; a construção ou reforma de inúmeras clínicas e hospitais privados, com financiamento da Previdência Social; a multiplicação de faculdades particulares de medicina por todo o país; a organização e a complementação da política de convênios entre o INPS e os hospitais, clínicas e empresas de prestação de serviços médicos, em detrimento dos recursos -já parcos -tradicionalmente destinados aos serviços públicos. Tais foram as orientações principais da política sanitária da conjuntura do 'milagre brasileiro' (LUZ, 1991, p. 81).
\end{abstract}

Por conseguinte, o cenário da saúde pública durante o regime militar foi que a medicina e o atendimento médico eram a fonte de cura das patologias e epidemias que assolavam o país, para tanto, os hospitais privados foram reformados com a verba da previdência social, houve um aumento das faculdades de medicina pelo país, a instituição e massificação de convênios entre INPS e demais hospitais e empresas prestadoras de serviços médicos, uma vez que os recursos públicos estavam se esvaindo.

As consequências das políticas de saúde adotadas são:

[...] a progressiva predominância de um sistema de atenção médica 'de massa' (no sentido de 'massificado') sobre uma proposta de medicina social e preventiva, que chegou a ser o discurso dominante na conjuntura anterior ao golpe de Estado; o surgimento e o rápido crescimento de um setor empresarial de serviços médicos, constituído por proprietários de empresas médicas centradas mais na lógica do lucro do que na da saúde ou da cura de sua clientela (este setor era, aliás, subsidiado em grande parte pelo Estado, ou seja, indiretamente pelos trabalhadores, na condição de contribuintes do fisco e da previdência social, através do desconto em folha). Assistimos também ao desenvolvimento de um ensino médico desvinculado da realidade sanitária da população, voltado para a especialização e a sofisticação tecnológica e dependente das indústrias farmacêuticas e de equipamentos médicohospitalares. Assistimos, finalmente, à consolidação de uma relação autoritária, mercantilizada e tecnificada entre médico e paciente e entre serviços de saúde e população (LUZ, 1991, p. 82).

Por conseguinte, as consequências das políticas da saúde evidenciam não só as mudanças nas escolhas políticas, como aspectos sociais e econômicos, em virtude da disseminação do ideal de combate as doenças ao invés de sua prevenção, a aderência econômica das questões de saúde por meio de empresas prestadoras de serviços médicos, o incremento da medicina em desacordo com a realidade social e sanitária, além de distante 
dela, resultando em uma relação autoritária, técnica e mercadológica entre a prestação dos serviços de saúde e a sociedade, o que é possível de se observar até hoje.

Aliás, diante dessa conjuntura, percebe-se que a população além de prejudicada estava claramente descontente, vez que as políticas sociais governistas não funcionavam, sendo apontadas como motivos da crise do regime. Não obstante, em 1983, a sociedade civil se organizou e foi às ruas reivindicar um Congresso "firme e atuante", e políticas sociais aptas a garantir direitos e cidadania aos brasileiros, dentre os quais o direito à saúde, entendido como dever do Estado. Eis que, "pela primeira vez na história do país, a saúde era vista socialmente como direito universal e dever do Estado, isto é, como dimensão social da cidadania” (LUZ, 1991, p. 83-84).

$\mathrm{Na}$ década de 80, como consequência dos benefícios da época anterior, para os quais não houve previsão de financiamento para viabilizar o seu acesso, em especial para as populações rurais e assalariados urbanos, houve uma crise fiscal do sistema previdenciário, uma das alternativas debatidas era a extinção da assistência médica prevista nos regimes previdenciários, de tal maneira que a solução encontrada não foi nem a privatização dos serviços de saúde, e sequer a "hegemonia do serviço público", na verdade, deixaram de realizar mudanças estruturais, e por consequência, intensificou-se a carência dos beneficiários (CORDEIRO, 2004, p. 347).

Dessarte, a prestação dos serviços de saúde estava muito ligada à previdência social, visto que havia inúmeros institutos voltados a políticas sociais para atendimento dos grupos sociais urbanos e rurais, todavia, foi gerada uma crise financeira na base de financiamento dessas políticas, as quais apesar de reformuladas mantiveram-se no meio termo entre as concessões estatais e a iniciativa privada, tal como antes do regime militar, o que agravava a situação, pois apenas postergava a crise.

Ainda assim, em 1983, a sociedade decide se organizar e se reunir em prol da democracia, da cidadania e de seus direitos, que deveriam ser assegurados pelo Estado, motivo pelo qual se iniciam movimentos que, pela primeira vez, passam a considerar a saúde como um direito de todos e dever do Estado.

No final dos anos 80, houve uma grande participação popular na escolha dos objetivos constitucionais, em particular, os profissionais da saúde que ingressaram no serviço público com a finalidade de atender as pessoas menos favorecidas começaram a se organizar para estabelecer as principais bases de uma nova política de saúde em um congresso: a VIII Conferência Nacional de Saúde (CNS).Nela, esta nova política foi abordada no painel Saúde 
na Constituição, de modo que a partir da Conferência houve uma proposta de emenda popular apresentada à Assembleia Constituinte. Saliente-se que a iniciativa privada interessada na área da saúde também participou dos debates da Assembleia Constituinte, os quais resultaram na “estrutura constitucional da política de saúde pública no país" (DALLARI; NUNES JÚNIOR, 2010, p. 76).

Com efeito,

Toda esta efervescência democrática foi canalizada para os trabalhos da Assembléia Nacional Constituinte, que se iniciaram em 1987. Em boa medida, a construção de uma ordem institucional democrática supunha um reordenamento das políticas sociais que respondesse às demandas da sociedade por maior inclusão social e equidade. Projetada para o sistema de políticas sociais como um todo, tal demanda por inclusão e redução das desigualdades adquiriu as concretas conotações de afirmação dos direitos sociais como parte da cidadania (FLEURY, 2009, p. 745).

Com a redemocratização e o processo de criação da nova Constituição, os setores sociais começaram a se organizar em prol das áreas de seu interesse a fim de que elas fossem incluídas e garantidas no texto constitucional. No que tange à saúde, a VIII Conferência Nacional foi um grande momento de união daqueles que lutavam e trabalhavam com e pela saúde para a elaboração de uma nova política de saúde pública que funcionasse a atendesse as necessidades nacionais, especialmente na visão daqueles que estudavam e conviviam pelo trabalho com a saúde pública.

A Reforma Sanitária ocorreu graças à atuação de certos grupos, quais sejam: os médicos, as associações médicas, os partidos de esquerda, o movimento popular em saúde, o apoio da Igreja por comunidades eclesiásticas e parlamentares de expressiva atuação no Congresso (MENICUCCI, 2014, p. 80).

Os debates na VIII CNS apresentavam três sugestões de ações políticas e técnicas para a realização de uma Reforma Sanitária: lutavam pela inclusão da saúde no texto constitucional no capítulo da ordem social; movimentos táticos; e, "a mobilização da sociedade para a ampliação das bases sociais do Movimento Sanitário”, (CORDEIRO, 2004, p. 352).

No contexto da redemocratização e das escolhas políticas aptas a realização de uma reforma sanitária, Luz (1991, p. 85) identifica o surgimento de uma nova classe que merece atenção: 
A 'burguesia da saúde' pode ser caracterizada, quanto à sua composição, por proprietários de empresas, grandes hospitais e clínicas médicas privadas; grupos ligados aos serviços médicos destinados às empresas; grandes indústrias de equipamentos médicos, nacionais e internacionais; empresas multinacionais de produtos farmacêuticos; e, finalmente, grandes médicos liberais, defensores de uma ideologia privatista.

Desta feita, a burguesia da saúde, que até hoje compõe o núcleo social brasileiro, é formada por grandes empresários, donos de empresas, hospitais e clínicas particulares, grupos de prestação de serviços médicos as empresas, indústrias de medicamentos e produtos médico-hospitalares, multinacionais e médicos liberais.

Isso porque, a saúde enquanto direito de todos e dever do Estado não pode se sujeitar aos poderes econômicos e interesses políticos, visto que atende o cidadão, garantindo o exercício de sua via enquanto pessoa. Este é o efeito do sistema capitalista que precisa ser harmonizado diariamente pelos governantes e quiçá membros da justiça, a delimitação da saúde enquanto direito sem ser subjugada a interesses econômicos e políticos.

Destarte, acerca da Reforma Sanitária, conclui Sonia Fleury (2009, p. 746) que:

\begin{abstract}
A reforma sanitária no Brasil é conhecida como o projeto e a trajetória de constituição e reformulação de um campo de saber, uma estratégia política e um processo de transformação institucional. Emergindo como parte da luta pela democracia, a reforma sanitária já ultrapassa três décadas, tendo alcançado a garantia constitucional do direito universal à saúde e a construção institucional do Sistema Único de Saúde (SUS).
\end{abstract}

Então, a reforma sanitária consistiu um movimento a favor da modificação das políticas de saúde, em especial na e para a Constituição de 1988, de modo que o direito à saúde possa ser um direito reconhecido, previsto e pronto para ser efetivado. Bem assim, a partir da VIII Conferência Nacional de Saúde se buscou a inclusão da saúde no texto constitucional e os movimentos para sua implementação com massivo apoio popular.

A seu turno, a assistência social no Brasil passou por três fases históricas: o período do não-direito, do Brasil Colônia até a abolição da escravidão, em que a assistência era fruto de meras ações de caridade ligadas a Igreja; a segunda foi após a abolição a Revolução de 1930, na qual os trabalhadores urbanos e industriais batalhavam por seus direitos trabalhistas e previdenciários, ao mesmo tempo em que havia inúmeras pessoas excluídas dos efeitos da industrialização; e, a terceira fase foi do primeiro governo Vargas até a redemocratização em 1988, nela já existe um parâmetro de políticas de previdência social (GONÇALVES, 2010, p. 106-107). 
Logo, o Brasil passou, ao longo dos anos, por inúmeras mudanças de ideal político e econômico, muitas como fruto das instabilidades e dos problemas não resolvidos desde a Independência e que foram se prolongando, de modo que as ações e políticas de saúde se realizavam inicialmente aqueles que trabalhavam, porque eram entendidas como benefícios dos trabalhadores, e, apenas com um regime ditatorial que mascarava direitos sociais, sem se importar com direitos civis, vida, integridade, liberdade e dignidade humanas é que a sociedade brasileira percebeu que todos precisavam lutar por democracia, direitos e cidadania, por isso, a Constituição de 1988 é cidadã, estabelecendo e compondo os cidadãos brasileiros e todos que estão no território nacional como sujeitos de direito, em uma democracia.

\section{DO DIREITO À SAÚDE NA CONSTITUIÇÃO FEDERAL DE 1988}

Pois bem, em face à todo o período antecedente de construção do direito à saúde no Brasil permeado por políticas sociais e ações voltadas à saúde pública, faz-se mister verificar acerca da regulamentação e das políticas de saúde após a promulgação e conforme estabelece a Constituição Federal de 1988.

Nesse sentido, o direito à saúde na $\mathrm{CF} / 88$ é direito social e "é direito de todos e dever do Estado, garantido mediante políticas sociais e econômicas que visem à redução do risco de doença e de outros agravos e ao acesso universal e igualitário às ações e serviços para sua promoção, proteção e recuperação", consoante o disposto no artigo 196 (BRASIL,online).

A saúde além de estar elencada como um direito social no artigo $6^{\circ}$ da Carta Magna possui toda uma seção de artigos no capítulo da seguridade social e no título da ordem econômica e social.

Desta feita,

Os valores de preservação da vida humana, a garantia de níveis progressivamente
mais altos de saúde, a salvaguarda do patrimônio genético próprio, a proteção da
integridade física, mental e emocional, entre outros conduzem a atuação dos
particulares e dos Poderes Públicos na efetivação do direito à saúde. Com efeito,
impõem a abstenção de comportamentos lesivos à saúde, no mais amplo sentido,
assim como a promoção e a consecução de medidas tendentes a efetivar esse direito
fundamental social, inclusive mediante prestações materiais específicos
(FIGUEIREDO, 2007, p. 95).

Logo, o direito a saúde, consoante o pensamento da autora, envolve um núcleo muito grande de outros direitos e de abrangência desde o patrimônio genético a integridade física, 
emocional e mental, razão pela qual o Poder Público, incumbido de sua garantia e efetivação, deve realizar ações de para promoção, proteção e defesa do direito à saúde.

O direito à saúde é entendido como um direito de defesa, uma vez que impede intervenções irregulares pelo Estado e/ou terceiros na vida do seu titular, mas também determina que o Estado realize políticas públicas para sua efetivação em favor da população, no tocante "a toda e qualquer prestação indispensável para a realização concreta deste direito à saúde" (SARLET, 2007, p. 8).

Figueiredo (2007, p. 94) aponta que embora a normatividade do artigo 196 da Constituição seja voltada em especial para o Estado, ela não inibe o dever de promoção e respeito por parte dos indivíduos e da sociedade.

De tal maneira que, o Sistema Único de Saúde (SUS) é a instituição que detém a atribuição constitucional de zelar e fornecer instrumentos garantidores do direito à saúde de acordo com o artigo 200 da Constituição Cidadã $^{1}$.

O SUS trata-se de:

\begin{abstract}
um sistema público e nacional, baseado no princípio da universalidade, a indicar que à assistência à saúde deve atender a toda a população. Tem como diretrizes organizativas a descentralização, como comando único em cada esfera governamental; a integralidade do atendimento e a participação da comunidade. A Lei $\mathrm{n}^{\circ}$ 8080/90, dispôs sobre as condições, a organização das ações e o funcionamento dos serviços de saúde, tendentes à realização da promoção, proteção e recuperação da saúde. Este diploma prescreve normas sobre: (a) organização, direção e gestão do SUS; (b) competências e atribuições de cada uma das três esferas federativas; (c) funcionamento e participação complementar dos serviços privados de assistência à saúde; (d) política de recursos humanos a ser adotada pelo SUS; (e) recursos financeiros, incluindo a respectiva gestão, planejamento e orçamento desses (FIGUEIREDO, 2007, p. 97).
\end{abstract}

Com efeito, a Lei $n^{\circ}$ 8.080/90 também é chamada de Lei do SUS, porque foi ela que instituiu e organizou esse sistema, completo e complexo no ordenamento jurídico brasileiro,

\footnotetext{
${ }^{1}$ Art. 200. Ao sistema único de saúde compete, além de outras atribuições, nos termos da lei:

I - controlar e fiscalizar procedimentos, produtos e substâncias de interesse para a saúde e participar da produção de medicamentos, equipamentos, imunobiológicos, hemoderivados e outros insumos;

II - executar as ações de vigilância sanitária e epidemiológica, bem como as de saúde do trabalhador;

III - ordenar a formação de recursos humanos na área de saúde;

IV - participar da formulação da política e da execução das ações de saneamento básico;

V - incrementar, em sua área de atuação, o desenvolvimento científico e tecnológico e a inovação;

VI - fiscalizar e inspecionar alimentos, compreendido o controle de seu teor nutricional, bem como bebidas e águas para consumo humano;

VII - participar do controle e fiscalização da produção, transporte, guarda e utilização de substâncias e produtos psicoativos, tóxicos e radioativos;

VIII - colaborar na proteção do meio ambiente, nele compreendido o do trabalho (BRASIL, online).
} 
após as diretrizes constitucionais.Dentre as atribuições do Sistema Único de Saúde estão à promoção, proteção e recuperação da saúde, dividido em competências a cada uma das três esferas de poder, a participação particular complementar e a gestão dos recursos financeiros de saúde. Além do que, o SUS detém como princípios a universalidade e a descentralização, ou seja, a assistência à saúde deverá ser proporcionada/ofertada a todos e cada esfera de poder detém sua participação e cota de responsabilidade na concretização da saúde.

O SUS, em seu aspecto histórico, também passou por modificações desde a promulgação da Constituição de 1988, uma vez que,no início, a política vigente era a da municipalização autárquica ou descentralização arco-íris, que irradiava da União para os municípios, sendo que o Ministério da Saúde lidava direta e frequentemente com os municípios buscando descentralizar as ações de saúde e implementar o SUS em todo o país, o que gerou uma competição entre os municípios por recursos e a distribuição ineficaz de recursos e serviços de saúde. Já no século XXI, há a tentativa de regionalização, a qual se mostrou de difícil consolidação. E, atualmente, vige a ideia dos pactos federativos a fim de construir redes de atenção (MENICUCCI, 2014, p. 89).

O contexto histórico de implantação do SUS denota que apesar da sua grandiosidade, não se esperava ou pressuponha tamanha dimensão da carência em saúde, igualmente as dificuldades burocráticas e políticas para sua implementação superaram o esperado, assim como o aporte e a distribuição de recursos e serviços públicos pelo território nacional.

Eis que, o serviço público é "instrumento concretizador dos direitos fundamentais do ser humano, a proporcionar vida digna, proclamada pela ordem constitucional como um dos elementos fundantes do Estado Democrático de Direito” (SERRANO, 2012, p. 90).

A importância do SUS não é apenas quanto ao fornecimento de medicamentos, cirurgias, tratamentos de saúde e que evitem o risco de patologias, ele simboliza o acolhimento por parte do Estado e a prestação de um serviço público em favor da garantia de um direito fundamental social (a saúde).

Destarte, existem políticas públicas delineadas pelo Estado, no âmbito do SUS (Sistema Único de Saúde), contendo uma lista de medicamentos denominada Relação Nacional de Medicamentos Essenciais (Rename), a qual serve de base para o tratamento das principais enfermidades que acometem a população, enquanto no tocante as doenças mais raras a lista de medicamentos é relacionada ao Programa de Medicamentos de Dispensação em Caráter Excepcional (VIEIRA, 2008, p. 36). 
Insta ressalvar que além da prestação de serviços públicos de saúde, a Constituição também abre espaço para a iniciativa privada no que diz respeito à complementação dos serviços, dado que o artigo 199 prevê a livre iniciativa privada para a assistência à saúde, ou uma atuação suplementar ao SUS, desde que haja contrato de direito público ou convênio, e preferencialmente as entidades filantrópicas e sem fins lucrativos (SERRANO, 2012, p. 94).

Pondera Serrano (2012, p. 96) que além do SUS, o Brasil possui agências reguladoras no âmbito da saúde, quais sejam: a ANVISA (Agência Nacional de Vigilância Sanitária), instituída pela Lei no 9.782/1999, na forma de autarquia vinculada ao Ministério da Saúde, e, a Agência Nacional de Saúde Suplementar (ANS), criada pela Lei nº 9.961, "autarquia de regime especial vinculada ao Ministério da Saúde, criada como órgão de regulação, normatização, controle e fiscalização, das atividades que garantam a assistência complementar à saúde".

Lidar com saúde pública não demanda apenas a criação de um sistema único para gerir, monitorar e executar políticas públicas de saúde como instrumentos de sua concretização, são necessárias também agências para verificar a qualidade sanitária dos produtos nacionais e internacionais que entram e estão no país, bem como estabelecer os limites e padrões sanitários brasileiros. Existe também uma agência destinada a normatizar e fiscalizar as questões no entorno da cobertura de saúde.

Por outro lado, o texto constitucional no tocante a saúde:

Evidenciaram-se na Constituição as visões antagônicas desses dois grupos de atores. Na época, suas posições eram simplificadas em dois termos: a estatizante, que era a perspectiva inovadora, daqueles que queriam a reforma da saúde, uma reforma no sentido de assumir o direito à saúde como obrigação a ser provida pelo Estado; e a privatizante, que representava os interesses e concepções surgidos na trajetória da política de saúde como efeito de feedback das próprias decisões governamentais do passado. Nesse sentido, as decisões de políticas públicas forjaram determinados atores e interesses que se colocarão como importante pontos de veto no momento da votação da Constituição, cujo texto refletiu os acordos que se conseguiu construir naquele momento. Ele apresenta, aliás, algumas ambiguidades jurídicas que apontam o ajustamento dessas alternativas inovadoras aos padrões consolidados. Como resultado a Constituição apresenta um sistema híbrido e segmentado: por um lado consagra a saúde como direito, garante a universalidade e acesso à assistência, amplia a responsabilidade estatal e define a estruturação de um sistema inclusivo; por outro, preserva a liberdade do mercado e garante a continuidade das formas privadas de assistência e independentes de qualquer intervenção governamental (MENICUCCI, 2014, p. 81).

Com base nos comentários da autora, é possível concluir que a Constituição Federal apesar de consagrar a garantia e efetivação do direito à saúde, ainda reflete uma base política 
e econômica heterogênea nesse aspecto, uma vez que consolida a participação do Estado e a iniciativa privada nas questões atinentes a saúde. O que por um lado pode ser interpretado como uma divisão de responsabilidades ou o reconhecimento do aspecto mercatológico da saúde, por outro a intervenção privada na saúde faz com que o poder público e a iniciativa particular devam manter uma linearidade na oferta e na qualidade do serviço, permitindo o aperfeiçoamento do serviço público de saúde a ser prestado.

Dessa forma,

na sociedade contemporânea o direito à saúde exige tanto a participação do Parlamento, legítimo representante dos interesses envolvidos tanto no processo de produzir e consumir quanto de controlar os riscos sanitários, como a participação dos cidadãos na elaboração e na implementação das normas e ações destinadas à promoção, à proteção e à recuperação da saúde (DALLARI, 2009, p. 14).

Os avanços da participação social e popular na saúde não podem ficar apenas na história, da mesma forma que a saúde depende da atuação política de governantes e parlamentares para ser efetivada, vez que um direito não pode apenas constar no texto constitucional, também deve ser efetivado como tal, isto é, a promoção, proteção e recuperação da saúde.

Nesse contexto, o Pacto pela Saúde foi firmado em 2006, e envolve outros três pactos: o pacto pela vida, que prima pela vida dos idosos, o controle dos cânceres de mama e colo do útero, as doenças epidêmicas e a mortalidade maternal e infantil; o pacto em defesa do SUS pretende a aprovação da Emenda Constitucional 29, acerca do financiamento do SUS, e a aprovação do orçamento consolidado entre União, estados e municípios; e, o pacto de gestão procura definir a responsabilidade de cada instância de gestão do SUS, regulamentar as diretrizes de gestão para a descentralização, regionalização, a programação pactuada e integrada, o financiamento, a participação e o controle social, a gestão do trabalho, a educação e o planejamento em saúde, de forma a fomentar o acordo entre as esferas estaduais e municipais, de acordo com Dallari (2009, p. 25).

Portanto, a Constituição de 1988 trouxe como um de seus grandes marcos a positivação do direito à saúde no título sobre e seguridade social, e ainda institucionalizou o Sistema Único de Saúde, cujas atribuições foram mais definidas na Lei $n^{\circ}$ 8080/90, como órgão gestor, promotor e regulamentador da saúde no Brasil, e em prol da qualidade do serviço conta-se com a ANVISA e a ANS. Definitivamente, o Poder Público abraçou a gestão da saúde, dando margem à atuação privada, bem como com os pactos demonstram os 
principais objetivos da saúde pública nacional a serem combatidos ou efetivados, de forma que o que se espera, diante de todo esse escorço histórico analisado é que haja uma boa prestação do serviço mediante a implementação e eficácia das políticas públicas de saúde e a participação social, reivindicando a qualidade do serviço e sua concretização.

\section{CONCLUSÕES}

Por conseguinte, o cenário histórico que implicou na positivação do direito à saúde na Constituição Federal de 1988 é marcado por um conjuntura política nacional instável no seu início, motivo pelo qual as primeiras Constituições no Brasil não eram fortes para se perpetuarem, e a ideia de promoção dos direitos humanos nas Constituição ocorreu em razão do trabalho, posto que o direito à saúde no Brasil era entendido como fruto do trabalho, uma contraprestação ao trabalhador pela realização de seu oficio.

Com o passar dos anos, foram sendo criados institutos de assistência ao trabalhador, nos quais havia o fornecimento de atendimento médico, e esta era a garantia da saúde. De outro lado, a saúde como assistência social era resultado de práticas de caridade da Igreja aos necessitados ou então, da previdência social.

No regime militar, os direitos sociais eram garantidos pelo governo como forma de promoção do regime, e via reflexa, para sua aceitação, porém, como sua efetivação não condizia com as garantias, problemas de financiamento e qualidade nos serviços, inclusive e em especial nos de saúde, fizeram com que a sociedade civil se reunisse reivindicando direitos, democracia e cidadania.

Enfim, promulgada a Constituição Cidadã de 1988, nela foram assegurados inúmeros direitos, dentre os quais o da saúde, que conta com o SUS para sua gestão, organização e promoção, visto que o Poder Público detém a atribuição de efetivar por políticas e ações a saúde. Então, ainda há muito para melhorar a fim de se atingir a total, eficiente e eficaz garantia do direito à saúde, que está arraigado à situação política e econômica do país, uma vez que ele depende de políticas públicas a cargo do Estado. Pelo menos, considerando o referencial histórico de sua positivação no Brasil, conscientização por parte da sociedade civil é notório que a partir do momento em que a sociedade se tornar consciente, e isso vem melhorando, existem indícios de que o caminho tomado está certo.

\section{REFERÊNCIAS}


BOBBIO, Norberto; MATTEUCCI, Nicola; PASQUINO, Gianfranco. Dicionário de Política. 11. ed., Brasília: Editora UnB, 1998. v.1.

BRASIL. Constituição (1988). Constituição da República Federativa do Brasil: promulgada em 5 de outubro de 1988. Disponível em:

http://www.planalto.gov.br/ccivil_03/constituicao/constituicaocompilado.htm. Acesso em: 27 jun. 2018.

COMPARATO, Fábio Konder. A afirmação histórica dos direitos humanos. 9. ed. São Paulo: Saraiva, 2015.

CORDEIRO, Hésio. O Instituto de Medicina Social e a luta pela reforma sanitária: contribuição à história do SUS. Physis: Revista de Saúde Coletiva, v. 14, p. 343-362, 2004. Disponível em: https://www.scielosp.org/scielo.php?pid=S0103-

73312004000200009\&script=sci_abstract\&tlng=pt\#ModalArticles. Acesso em: 14 jun. 2018.

DALLARI, Sueli Gandolfi; NUNES JÚNIOR, Vidal Serrano. Direito Sanitário. São Paulo: Editora Verbatim, 2010.

DALLARI, Sueli Gandolfi. A construção do direito à saúde no Brasil. Revista de Direito Sanitário, São Paulo, v. 9, n. 3, p. 9-34, nov. 2008. ISSN 2316-9044. Disponível em: http://www.revistas.usp.br/rdisan/article/view/13128. Acesso em: 27 jul. 2018.

FIGUEIREDO, Mariana Filchtiner. Direito fundamental à saúde: parâmetros para sua eficácia e efetividade. Porto Alegre: Livraria do Advogado Editora, 2007.

FLEURY, Sonia. Reforma sanitária brasileira: dilemas entre o instituinte e o instituído.Ciênc. saúde coletiva, Rio de Janeiro,v. 14, n. 3, p. 743-752, junho de 2009. Disponível em: http://www.scielo.br/scielo.php?script=sci_arttext\&pid=S141381232009000300010\&lng=en\&nrm=iso. Acesso em: 16 jul. 2018.

GONÇALVES, Cláudia Maria da Costa. Direitos Fundamentais Social: uma releitura de uma constituição dirigente. 2. ed. rev. e atual. Curitiba: Juruá, 2010.

LAFER, Celso. A reconstrução dos direitos humanos: a contribuição de Hannah Arendt.

Estudos avançados, v. 11, n. 30, p. 55-65, 1997. Disponível em:

http://www.scielo.br/scielo.php?script=sci_arttext\&pid=S010340141997000200005\&lng=en \&nrm=iso. Acesso em: 07 maio2014.

LÉRIAS, Reinéro Antonio. As Constituições brasileiras: direitos fundamentais e cidadania. In: ALVES, Fernando de Brito; CAMBI, Eduardo A. S.; KLOCK, Andrea B. (orgs.).Direitos fundamentais revisitados. Curitiba: Juruá Editora, 2008, p. 191-264.

LUZ, Madel Therezinha. Notas sobre as políticas de saúde no Brasil de"Transição Democrática": anos 80. Physis: Revista de Saúde Coletiva, v. 1, n. 1, p. 77-96, 1991.

Disponível em: https://www.scielosp.org/pdf/physis/1991.v1n1/77-96/pt. Acesso em: 24 jun. 2018. 
MENICUCCI, Telma Maria Gonçalves. História da reforma sanitária brasileira e do Sistema Único de Saúde: mudanças, continuidades e a agenda atual. História, Ciências, Saúde Manguinhos, Rio de Janeiro, v.21,n.1, jan.-mar. 2014, p.77-92. Disponível em:http://www.scielo.br/pdf/hcsm/v21n1/0104-5970-hcsm-21-1-00077.pdf. Acesso em: 24 jun. 2018.

SARLET, Ingo Wolfgang. Algumas considerações em torno do conteúdo, eficácia e efetividade do Direito à saúde na Constituição de 1988. Revista Eletrônica sobre a Reforma do Estado (RERE), Salvador, Instituto Brasileiro de Direito Público, $\mathrm{n}^{\circ} 11$, setembro/outubro/novembro, 2007. Disponível em:

http://www.direitodoestado.com.br/artigo/ingo-wolfgang-sarlet/algumas-consideracoes-emtorno-do-conteudo-eficacia-e-efetividade-do-direito-a-saude-na-constituicao-de-1988. Acesso em: 24 abr. 2018.

SERRANO, Mônica de Almeida Magalhães. O sistema único de saúde e suas diretrizes constitucionais. 2. ed. São Paulo: Editora Verbatim, 2012.

VIEIRA, Fabiola Sulpino. Ações judiciais e direito à saúde: reflexão sobre a observância aos princípios do SUS. Rev. Saúde Pública, São Paulo, v. 42, n. 2, p. 365-369, abr. 2008. Disponível em: http://www.scielo.br/scielo.php?script=sci_arttext\&pid=S003489102008000200025\&lng=pt\&nrm=iso. Acesso em: 26 abr. 2018. 